\title{
Break Out the World's Smallest Violin for an Overwhelmed Neuroradiologist
}

W hen the world seemingly stopped turning in early March 2020, I anticipated many life changes, most involving isolation and a slowing of routine activities, both professional and personal. As my husband and I transported my (astoundingly) heavy Barco monitor and workstation to our weekend place at the shore, I knew that the sort of elective and semi-elective head and neck imaging that has made up the bulk of my practice would likely slow significantly. I am (and sincerely hope I am still) at a relatively late stage of my career and had been thinking a lot about how I needed to slow down and carve out some more time for myself. I imagined extricating myself from all academic activities that didn't "spark joy" and spending more time looking at cases and talking to referrers, my first and primary love in radiology. Maybe I'd finish up the case series manuscript I had started (mumbles into hand) a number of years ago. I'd certainly catch up on my reading and exercise. We had been talking a lot about retiring to the shore and figured that the time spent here during quarantine would give us an opportunity to see if the local offerings would be enough stimulation for us city folk. In short, I imagined that this episode would be great practice for upcoming retirement.

Turns out I could not have been more wrong. Although neuroimaging volumes plummeted, my colleagues and I, who now spoke more via text and Microsoft Teams than we ever did in person, started to think about COVID-19 and how we could explain some of the things we were seeing. Where have all the stroke codes gone? Why can't people smell-should we look at the olfactory bulbs? This prompted furious races (with every other academic physician on the planet) to apply for institutional review boards, collect data, and start constructing manuscripts. Never mind that I previously hated writing data-driven papers; this was something entirely new and completely fascinating!

http://dx.doi.org/10.3174/ajnr.A6786
Then professional societies started calling. How will we turn our annual meeting virtual? Will we need to do so for next year as well? How can we prepare our society for vast changes in its activities and finances and, hey, how about some webinars? The proliferation of webinars may be the most simultaneously rewarding and vexing change in our professional landscape. How does Zoom work? How do I record my lectures in PowerPoint? How many times do I need to re-record given this annoying hiss and that choppy transition? Who knew people talked so much between slides?

In addition to death and taxes, there are some things that you can always count on, such as on-line training modules for infection control (ironic), fire safety, information technology phishing, and so on. Then the medical staff office comes calling with your recredentialing packet. There are physician time studies and resident reviews. Somehow, the consults kept coming in despite the absence of elective surgery (wishful thinking?). When the volumes finally started increasing again, you felt like you never really had a break. All this on top of shopping and meal prep for 3 meals a day, a challenge for New Yorkers used to eating out as often as in, and, of course, all that cleaning. So, so much cleaning.

I am, of course, eternally grateful that my loved ones and I are safe, that I have a wonderful job, that I wake every morning to the sunrise over the beach and end each day watching the sun set over our leafy town. Alas, we are only human. We need to acknowledge that although we may have the best intentions, we may occasionally succumb to small and sometimes petty annoyances, like the ones listed above. Can you eke out a little sympathy and play me a tune on the world's smallest violin?

I'd like to acknowledge my husband Doug Phillips both for his help with edits and for putting up with me during quarantine.

(1)D.R. Shatzkes

Department of Radiology Lenox Hill Hospital, Zucker School of Medicine at Hofstra/Northwell New York, New York 